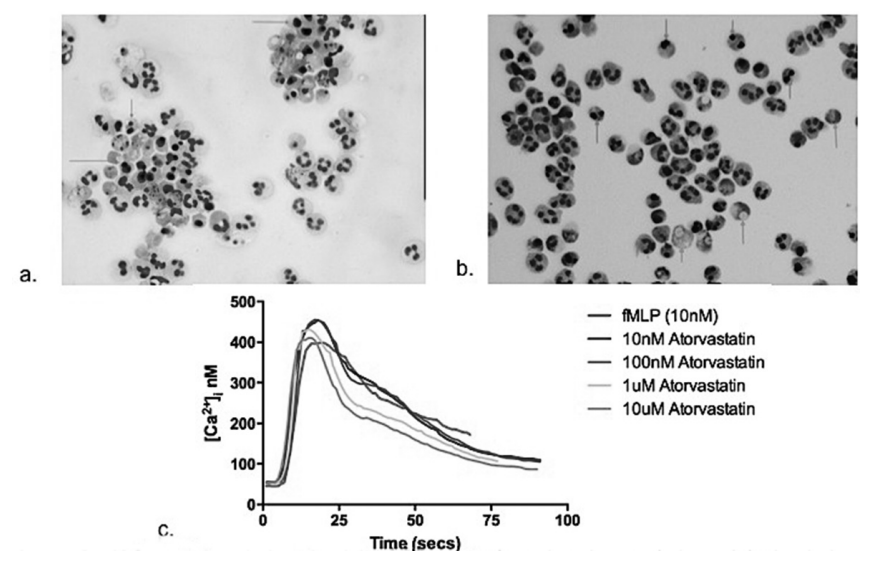

Abstract S16 Figure 1 Cytospin of control neutrophils at 20 hrs apoptosis; b. cytospin of atorvastatin treated neutrophils at $20 \mathrm{hrs}$ apoptosis; (red arrows indicate apoptotic neutrophils; blue arrows indicate 'ghost'cells) $\mathrm{C}$. dose response curve of fMLP induced increase in $\left[\mathrm{Ca}^{2+}\right] \mathrm{l}$ flux; reduced by Atorvastatin in a dose dependent manner. $\mathrm{fMLP}=$ formyl-Methionyl-Leucinyl-Phenylalanine

allocated to receive either atorvastatin $(80 \mathrm{mg})$ or a placebo, orally once a day for 6 months. Primary endpoint was reduction in cough from baseline to 6 months, measured by the Leicester Cough Questionnaire (LCQ) score (range 3-21; 3 severe cough; minimum clinically important difference, 1.3 units).

Findings (i) RCT 30 individuals were assigned atorvastatin and 30 were allocated placebo. There was evidence of a difference in baseline to 6-month change in LCQ between the treatment groups, with a significant improvement in the statin treated group, with a mean difference $2.2,95 \%$ CI for difference $(0.5$, 3.9) $\mathrm{p}=0.01$.

When analysed as proportion of improvement in LCQ, in the statin treated group $40 \%$ patients had a 1.3 Units or more improvement in the LCQ compared with $17 \%$ in the placebo group; difference in proportion 23\% (95\% CI for difference $1 \%, 45 \%), \mathrm{p}=0.04$.

There was significantly increased number of apoptotic airway neutrophils [mean difference of 8.9 (11.7); p = 0.04] with a trend towards a decreased total number of neutrophils in the sputum; $\mathrm{p}=0.09$; in statin treated group.

(ii) In vitro studies

Statins enhance apoptosis of neutrophils in vitro due to a reduction in stimuli induced increase in calcium flux.

Interpretation 6 months of atorvastatin improved cough on a quality-of-life scale in patients with bronchiectasis. Multicentre studies are now needed to assess whether long-term statin treatment can reduce exacerbations. Further studies are needed to establish if statins regulate $\mathrm{Ca}^{2+}$ flux by altering the intracellular or extracellular pathways.

\section{S17 CARDIOVASCULAR RISK FACTORS IN PEOPLE WITH BRONCHIECTASIS: A CROSS SECTIONAL STUDY}

${ }^{1} V$ Navaratnam, ${ }^{1} E$ Millett, ${ }^{2} J R$ Hurst, ${ }^{1} S L$ Thomas, ${ }^{1} L$ Smeeth, ${ }^{3}$ RB Hubbard, ${ }^{2}$ B Brown, ${ }^{1} \mathrm{JK}$ Quint. ${ }^{1}$ Faculty of Epidemiology and Population Health, London School of Hygiene and Tropical Medicine, UK, London, UK; ${ }^{2}$ Centre for Inflammation and Tissue Repair, University College London, London, UK; ${ }^{3}$ Division of Epidemiology and Public Health, University of Nottingham, Nottingham, UK

10.1136/thoraxjnl-2014-206260.23

\begin{tabular}{|c|c|c|c|c|c|}
\hline $\begin{array}{l}\text { Cardiovascular risk factor or prescription } \\
\text { of cardiovascular medication }\end{array}$ & & $\begin{array}{l}\text { Number of people } \\
(\%)(n=3,895,800)\end{array}$ & $\begin{array}{l}\text { Number without bronchiectasis } \\
(\%)(n=3,884,858)\end{array}$ & $\begin{array}{l}\text { Number with bronchiectasis } \\
(\%)(n=10,942)\end{array}$ & $\begin{array}{l}\text { Adjusted odds } \\
\text { ratio* }(95 \% \mathrm{Cl})\end{array}$ \\
\hline \multirow[t]{4}{*}{ Smoking status } & Never smoker & $773,094(19.8)$ & $768,975(19.8)$ & 4119 (37.6) & 1.00 \\
\hline & Ex-smoker & $296,223(7.6)$ & $293,072(7.5)$ & $3151(28.8)$ & $1.30(1.23-1.36)$ \\
\hline & Current smoker & $605,205(15.5)$ & $601,533(15.5)$ & 3672 (33.6) & $0.88(0.84-0.92)$ \\
\hline & Missing data & $2,221,278(57.0)$ & $2,221,278(57.2)$ & 0 & - \\
\hline \multirow[t]{2}{*}{ Hypertension } & No & $3,200,460(82.1)$ & $3,193,289(82.2)$ & $7171(65.5)$ & 1.00 \\
\hline & Yes & $695,340(17.9)$ & $691,569(17.8)$ & $3771(34.5)$ & $0.94(0.90-0.98)$ \\
\hline \multirow[t]{2}{*}{ Hypercholesterolemia } & No & $3,643,743(93.5)$ & $3,634,097(93.5)$ & $9646(88.2)$ & 1.00 \\
\hline & Yes & $252,057(6.5)$ & $250,761(6.5)$ & $1296(11.8)$ & $0.94(0.89-0.98)$ \\
\hline \multirow[t]{2}{*}{ Diabetes } & No & $3,708,873(95.2)$ & $3,698,882(95.2)$ & 9991 (91.3) & 1.00 \\
\hline & Yes & $187,281(4.8)$ & $186,330(4.8)$ & $951(8.7)$ & $0.97(0.91-1.04)$ \\
\hline \multirow[t]{2}{*}{ Family history of cardiovascular disease } & No & $3,104,934(79.7)$ & $3,096,973(79.7)$ & $7961(92.8)$ & 1.00 \\
\hline & Yes & $790,866(20.3)$ & $787,885(20.3)$ & $2981(27.2)$ & $1.14(1.07-1.19)$ \\
\hline \multirow[t]{2}{*}{$\beta$ blockers } & No & $3,350,205(86.0)$ & $3,339,303(86.0)$ & $10,902(99.6)$ & 1.00 \\
\hline & Yes & $545,595(14.0)$ & $545,555(14.0)$ & $40(0.4)$ & $0.02(0 . .01-0.03)$ \\
\hline \multicolumn{6}{|l|}{ Angiotensin converting enzyme (ACE) inhibitor } \\
\hline \multirow[t]{2}{*}{ or Angiotensin II receptor blocker } & No & $3,448,012(88.5)$ & $3,437,161(88.5)$ & $10,860(99.3)$ & 1.00 \\
\hline & Yes & $447,770(11.5)$ & $447,697(11.5)$ & $82(0.8)$ & $0.03(0.02-0.04)$ \\
\hline \multirow[t]{2}{*}{ Nitrates } & No & $3,732,559(95.8)$ & $3,772,786(95.8)$ & $9773(89.3)$ & 1.00 \\
\hline & Yes & $163,241(4.2)$ & $162,072(4.2)$ & $1169(10.7)$ & $1.29(1.21-1.38)$ \\
\hline \multirow[t]{2}{*}{ Calcium channel blockers } & No & $3,572,373(91.7)$ & $3,563,365(91.7)$ & $9008(82.3)$ & 1.00 \\
\hline & Yes & $323,427(8.3)$ & $321,493(8.3)$ & $1934(17.7)$ & $1.02(0.97-1.08)$ \\
\hline \multirow[t]{2}{*}{ Anti-platelets } & No & $3,446,225(88.5)$ & $3,435,850(88.4)$ & $10,375(94.8)$ & 1.00 \\
\hline & Yes & $449,575(11.5)$ & 449,008 (11.6) & $567(5.2)$ & $0.14(0.13-0.15)$ \\
\hline \multirow[t]{2}{*}{ Lipid lowering drugs } & No & $3,423,738(87.9)$ & $3,413,209(87.9)$ & $10,527(96.2)$ & 1.00 \\
\hline & Yes & $472,062(12.1)$ & $471,649(12.1)$ & $413(3.8)$ & $0.11(0.10-0.12)$ \\
\hline
\end{tabular}

${ }^{*}$ Odds ratios adjusted for age and sex 
Background We have previously demonstrated that individuals with bronchiectasis have a higher prevalence of cardiovascular disease compared to the general population. ${ }^{1}$ It is unclear if this is due higher prevalence of cardiovascular risk factors amongst people with bronchiectasis or through other mechanisms.

Methods We conducted a cross-sectional study using electronic primary care data from the Clinical Practice Research Database (CPRD-GOLD) to estimate the prevalence of cardiovascular risk factors (smoking habit, diabetes, hypertension, hyperlipidaemia, family history of cardiovascular disease) and medication commonly prescribed to manage cardiovascular disease amongst people with and without bronchiectasis. Logistic regression was used to generate odds ratios for each risk factor or cardiovascular drug, adjusting for age and sex.

Results Approximately 3.9 million individuals were included in our study, 10,942 $(0.3 \%)$ of which had a record of bronchiectasis. Individuals with bronchiectasis were predominantly female $(60.4 \%)$ and the median age at time of diagnosis was 56.2 (Interquartile range: 40.6-67.5) years. The prevalence of hypertension, diabetes and hypercholesterolaemia was slightly lower in individuals with bronchiectasis. We also found that people with bronchiectasis were less likely to have prescriptions for beta blockers, angiotensin converting enzyme inhibitors or angiotensin II receptor blockers, anti-platelets and lipid lowering drugs (see Table 1).

Conclusions Patients with bronchiectasis have a lower prevalence of cardiovascular risk factors compared to the general population. This raises the possibility that other factors associated with bronchiectasis could be contributing to the increase risk in cardiovascular disease.

\section{REFERENCE}

1 Navaratnam V, Millett E, Hurst JR, Thomas S, Smeeth L, Hubbard R, Brown JS, Quint JK. The association between bronchiectasis and cardiovascular disease: A population based study. American Journal of Respiratory and Critical Care Medicine 2014; 189:A3618

\section{COPD investigations}

\section{S18 RATE OF DECLINE IN LUNG DENSITY MAY PREDICT LONG-TERM OUTCOME IN PATIENTS WITH ALPHA 1 ANTITRYPSIN DEFICIENCY (AATD)}

${ }^{1} \mathrm{CE}$ Green, ${ }^{2} \mathrm{D}$ Parr, ${ }^{1}$ RA Stockley, ${ }^{1} \mathrm{AM}$ Turner. ${ }^{1}$ University of Birmingham, Birmingham, UK; ${ }^{2}$ University Hospitals Coventry and Warwickshire NHS Trust, Coventry, UK

\subsection{6/thoraxjn-2014-206260.24}

introduction and objectives Alpha-1-Antitrypsin Deficiency (A1ATD) is a genetically determined anti-proteinase deficiency which predisposes to emphysema. ${ }^{1}$ Factors predicting mortality in untreated A1ATD patients include poor FEV1, gas transfer and low lung density. ${ }^{1}$ Indeed the latter has been shown to be the most sensitive measure of progression and hence has become the primary outcome in recent studies of augmentation therapy. ${ }^{2}$ We hypothesised that patients with the most rapid decline in lung density would be those most at risk of death and most in need of transplantation as the only viable rescue option.

Methods Augmentation naïve patients with 2 quantitative CT scans were selected from the UK A1ATD registry. The annual decline in lung density was determined using the difference between the 2 scans and patients were divided into those with no decline, a slow decline $(0-2 \mathrm{~g} / \mathrm{l} /$ year $)$ or a rapid decline $(>2)$. Subsequent death or lung transplant was noted.

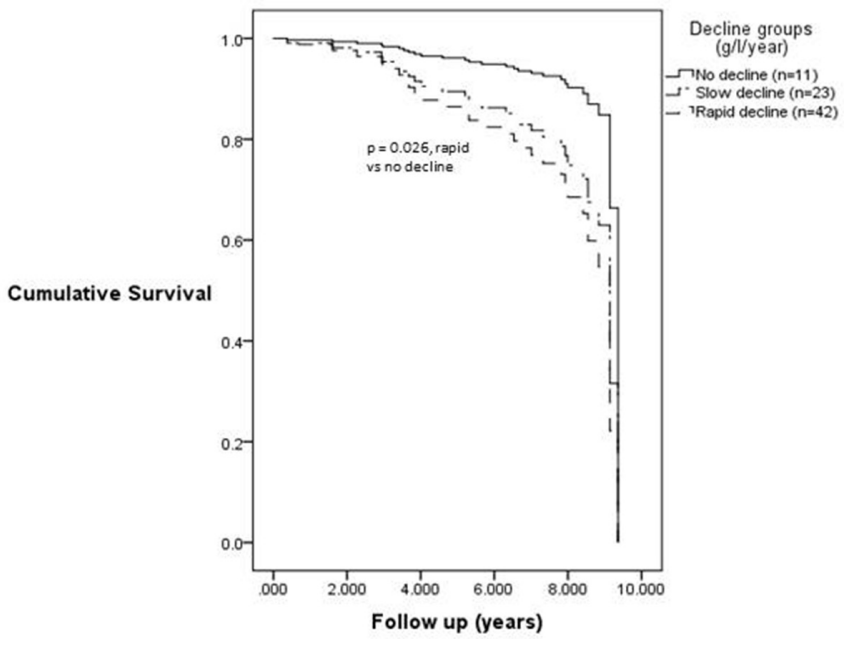

Abstract S18 Figure 1 Cox regression analysis

A univariate analysis was undertaken dividing the population into 2 groups: Alive without transplant and dead. Median baseline density was significantly higher in the living than the dead group (55.40 g/l and $39.80 \mathrm{~g} / \mathrm{l}$ respectively; $\mathrm{p}=0.002)$ and thus was included in a multivariate analysis, seeking association with subsequent death in a Cox regression analysis.

Results 77 patients were identified with sufficient data for analysis. 27 had died and 1 was transplanted and excluded from further analysis.

Slow decline in densitometry showed a trend to lower survival compared to no decline $(\mathrm{p}=0.065)$ but rapid decline was significantly associated with death $(\mathrm{p}=0.026$; Figure).

Conclusions Decline in lung density may be a suitable surrogate measure for survival in AATD, and as augmentation therapy slows the decline in lung density ${ }^{2}$ could identify a group more likely to benefit from augmentation in the shorter term.

\section{REFERENCES}

1 Dawkins $\mathrm{P}$, et al. Mortality in alpha-1-antitrypsin deficiency in the UK. Respir Med. 2009 Oct; 103(10):1540-7

2 Stockley RA, et al. Therapeutic efficacy of alpha-1 antitrypsin augmentation therapy on the loss of lung tissue: an integrated analysis of 2 randomised clinical trials using computed tomography densitometry. Respir Res. 2010;11:136

\section{S19 IMAGING DERIVED REGIONAL LUNG FUNCTION USING HYPERPOLARISED XENON MRI (XE-MRI) AND QUANTITATIVE COMPUTED TOMOGRAPHY (QCT) IN CHRONIC OBSTRUCTIVE PULMONARY DISEASE (COPD)}

${ }^{1} \mathrm{TN}$ Matin, ${ }^{2} \mathrm{X} \mathrm{Xu},{ }^{2} \mathrm{~T}$ Doel, ${ }^{2} \mathrm{~V}$ Grau, ${ }^{1} \mathrm{~N}$ Rahman, ${ }^{1} \mathrm{~A}$ Nickol, ${ }^{1} \mathrm{FV}$ Gleeson. ${ }^{1}$ Oxford University Hospitals NHS Trust, Oxford, UK; ${ }^{2}$ University of Oxford, Oxford, UK

\subsection{6/thoraxjnl-2014-206260.25}

Introduction and objectives To derive quantitative regional imaging lung function parameters using hyperpolarised xenon MRI (Xe-MRI) and computed tomography (QCT), and compare these to pulmonary function tests (PFTs) in subjects with chronic pulmonary obstructive disease (COPD).

Methods Twenty patients with COPD (stage II - IV GOLD criteria classification) underwent Xe-MRI at 1.5T, QCT, and PFTs.

Whole lung and lobar percentage ventilated volumes were obtained using automated segmentation of multi-slice Xe-MRI ventilation images acquired at a breath hold of FRC $+1 \mathrm{~L}$ using in-house software. Average whole lung apparent diffusion coefficients (ADCs) were calculated from multi-slice Xe-MRI 